\title{
CARACTERIZAÇÃO DA MATÉRIA ORGÂNICA DO SOLO EM FRAGMENTOS DE MATA ATLÂNTICA E EM PLANTIOS ABANDONADOS DE EUCALIPTO( ${ }^{(1)}$
}

\author{
Cristiana do Couto Miranda ${ }^{(2)}$, Luciano Pasqualoto Canellas $^{(3)} \&$ \\ Marcelo Trindade Nascimento ${ }^{(4)}$
}

\begin{abstract}
RESUMO
A compreensão da dinâmica da matéria orgânica (MO) nos ecossistemas de Mata Atlântica é necessária para o manejo eficiente e conservação de vegetações nativas. A natureza química das substâncias húmicas (SHs) reflete os processos de gênese e uso do solo e pode ser usada como indicador da qualidade da MO. O objetivo deste estudo foi usar a qualidade da MO como sinalizador do ambiente edáfico em áreas de mata nativa, sobre Gleissolo Háplico Tb distrófico, argissólico e Cambissolo Háplico Tb distrófico, e em plantios abandonados de eucalipto de diferentes idades, sobre Argissolo Vermelho-Amarelo distrófico latossólico, localizados na Reserva Biológica União, RJ. Para isso, foram avaliadas as distribuições da MO humificada e os ácidos húmicos do solo por meio de métodos químicos e espectroscópicos, em duas profundidades do solo (0-0,10 e 0,10-0,20 m). Os solos da Reserva Biológica apresentaram fertilidade natural muito baixa, condição esta limitante para o processo de humificação. As SHs representaram, portanto, menos de $50 \%$ do carbono prontamente oxidável, indicando que as substâncias não-húmicas compõem a maior parte da MO; portanto, a serrapilheira tem o papel central na nutrição das plantas e microrganismos. A distribuição relativa das frações que compõem a MO humificada não foi alterada pela cobertura vegetal nem pela classe de solo. Os ácidos húmicos apresentaram natureza química semelhante à normalmente encontrada para os ácidos fúlvicos, e tais características foram expressas no baixo conteúdo de $\mathrm{C}$ e nos elevados valores das razões $\mathrm{H} / \mathrm{C}$ e $\mathrm{O} / \mathrm{C}$ e da acidez, o que levou à formação de material humificado pouco condensado.
\end{abstract}

\footnotetext{
(1) Parte da Tese de Mestrado em Produção Vegetal do primeiro autor, apresentada à Universidade Estadual do Norte Fluminense Darcy Ribeiro em março de 2005. Recebido para publicação em março de 2006 e aprovado em maio de 2007.

${ }^{(2)}$ Laboratório de Solos da Universidade Estadual do Norte Fluminense Darcy Ribeiro - UENF. Av. Alberto Lamego 2000, Horto, CEP 28013-600 Campos dos Goytacazes (RJ). E-mail: coutomiranda@yahoo.com.br

(3) Laboratório de Solos, UENF. E-mail: canellas@uenf.br

(4) Laboratório de Ciências Ambientais, UENF. E-mail: mtn@uenf.br
} 
A espectroscopia de infravermelho indicou o efeito do tipo de solo e da cobertura vegetal sobre a qualidade química dos ácidos húmicos. O material humificado isolado da Mata Atlântica apresentou maior intensidade de fluorescência, sugerindo maior labilidade e capacidade de ceder elétrons para reações químicas do solo.

Termos de indexação: substâncias húmicas, fertilidade, solos florestais, solos tropicais.

\title{
SUMMARY: QUALITY OF SOIL ORGANIC MATTER IN FRAGMENTS OF ATLANTIC FOREST AND ABANDONED EUCALYPTUS PLANTATIONS
}

\begin{abstract}
The organic matter dynamics in Atlantic forest ecosystems must be understood to ensure the efficiency of conservation programs. Chemical characteristics of humic substances are important because they reflect the soil genesis processes and soil management, and can be used as indicator of the organic matter quality. The purpose of this study was to test the organic matter quality as a marker of the soil environment in areas of native Atlantic forest developed on a distrophyc Gleysol and a distrophyc Cambisol and in abandoned plantations of eucalyptus of different ages, at the União Biological Reserve, RJ, Brazil. The distribution of the humified fractions of the soil organic matter and humic acids were evaluated by chemical and spectroscopic methods, in two soil layers $(0-0.10$ and $0.10-0.20 \mathrm{~m}$ ). Soil fertility of the Biological Reserve was very low, representing a limiting factor for the humification process. Humic substances represented less than $50 \%$ of the oxidized carbon, indicating that most of the organic matter consists of non-humic substances. Consequently, forest litterfall plays a central role in the plant/microorganism nutrition. The relative distribution of the humic fraction was not altered by the plant cover or soil class. The chemical nature of the humic acids was similar to fulvic acids. These characteristics were expressed by a low carbon content, high $\mathrm{H} / \mathrm{C}$ and $\mathrm{O} / \mathrm{C}$ ratios and high acidity values which resulted in humified material with low chemical evolution. Infrared spectroscopy indicated the effect of the soil class and plant cover on the chemical quality of the humic acids. The fluorescence intensity of humified material isolated from the Atlantic forest area was high, suggesting higher lability and capacity to release electrons for chemical reactions in the soil.
\end{abstract}

Index terms: humic substances, fertility, forest soil, tropical soils.

\section{INTRODUÇÃO}

A preocupação com a conservação e restauração da Mata Atlântica vem crescendo nos últimos anos, em virtude da ameaça de extinção das áreas desse ecossistema. Nos ambientes tropicais e subtropicais de ocorrência natural da Mata Atlântica há predominância de solos altamente intemperizados, e a matéria orgânica do solo (MOS) tem papel fundamental na sua fertilidade. Por sua vez, as substâncias húmicas (SHs) constituem a maior parcela do compartimento de carbono (C) estável da MOS.

A maior parte dos resíduos vegetais, quando chegam ao solo, é rapidamente transformada, podendo ainda sofrer seqüestro pela fração mineral ou transformação bioquímica por meio do processo genericamente conhecido como humificação. Tanto a mineralização como a humificação são dependentes da atividade biológica. De acordo com Cerri \& Volkoff
(1988), os principais fatores que controlam a formação do húmus são a temperatura, presença ou ausência de cátions básicos no solo, nitrogênio e drenagem. Esses são os fatores que mais influenciam a atividade biológica, os quais podem variar conforme o ambiente e a ação antrópica.

As diferentes frações de carbono orgânico humificado do solo apresentam características químicas, físicas e morfológicas distintas, e a distribuição dessas frações pode indicar a qualidade da MOS (Lima, 2004). Os ácidos húmicos (AHs), constituintes das SHs, são compostos estáveis, ou seja, de difícil degradação (Stevenson, 1994). Esses compostos interagem com o meio circundante, interferindo nas propriedades químicas, físicas e biológicas do solo (Canellas, 1999). São, portanto, um sinalizador natural do processo de humificação e refletem tanto a condição de gênese como a de manejo do solo (Zech et al., 1997). 
A caracterização da qualidade dos $\mathrm{AHs}$ pode auxiliar na compreensão da MOS, funcionando como um indicador do ambiente solo. Assim, um monitoramento mais eficiente poderá aprimorar o uso das estratégias de recuperação dos solos, conservação e ampliação dos remanescentes de Mata Atlântica.

O objetivo deste trabalho foi avaliar a distribuição das frações húmicas e as características químicas e espectroscópicas dos AHs extraídos dos solos de fragmentos de mata nativa e de plantios abandonados de eucalipto de diferentes idades.

\section{MATERIAL E MÉTODOS}

As áreas estudadas foram dois fragmentos de Mata Atlântica de Baixada - denominados mata alagada (A) $\left(22^{\circ} 26^{\prime} 22,6\right.$ ” S e $42^{\circ} 01^{\prime} 24,8$ ” W), com solos encharcáveis na época chuvosa, e mata de morrote (B) $\left(22^{\circ} 26\right.$ ' 18,8 " S e $42^{\circ} 03^{\prime} 06,7$ ' W), presente no perfil arredondado do relevo - e três áreas de plantios de eucalipto (Corymbia citriodora) em diferentes idades (com 14, 16 e 18 anos, denominadas áreas $\mathrm{C}, \mathrm{D}$ e E), abandonados há nove anos, localizadas na Reserva Biológica União, entre Rio das Ostras e Casimiro de Abrel-RJ (Figura 1). A área "C" está situada a $22^{\circ} 25^{\prime}$ ' 53,1 " S e $42^{\circ} 02$ ' 29,1 " W; "D", a $22^{\circ} 25$ ' 41,1 ” S e $42^{\circ} 02$ ' 07,8 "W; e "E", a $22^{\circ} 26^{\prime} 24,9$ " S e $42^{\circ} 01$ ' 12,2 " W. Todas as áreas possuem altitude inferior a $150 \mathrm{~m}$. Segundo histórico dessa Reserva Biológica, a calagem foi realizada anteriormente ao plantio dos eucaliptos (C e E). Na região predomina o clima tropical úmido, a pluviosidade anual varia de 1.100 a $2.000 \mathrm{~mm}$ e a temperatura média anual é de $22^{\circ} \mathrm{C}$ (Figura 2). Os solos presentes nessas áreas foram classificados, em loco, como: Argissolo Vermelho-Amarelo distrófico latossólico (sob os eucaliptos), Gleissolo Háplico Tb distrófico argissólico (sob a área A) e Cambissolo Háplico Tb distrófico argissólico (sob a área B), de acordo com o Sistema Brasileiro de Classificação de Ciência do Solo (Embrapa, 1999). Com uso de trado holandês, os solos foram amostrados em duas profundidades $(0-0,10$ e $0,10-0,20 \mathrm{~m})$. Em cada área foram feitas três amostras compostas, formadas por 10 amostras simples. Essas amostras foram acondicionadas em sacolas de plástico devidamente identificadas e, posteriormente, secadas ao ar, destorroadas e passadas em peneira $(2 \mathrm{~mm})$. Essas amostras foram avaliadas por meio de análises químicas, segundo Embrapa (1997).

O fracionamento da MOS foi realizado a partir da simplificação do método de Belchikova-Kononova, descrito por Guerra \& Santos (1999). As amostras de solo passaram por pré-tratamento com ácido ortofosfórico $2 \mathrm{~mol} \mathrm{~L}^{-1}$ na proporção 1: $10(\mathrm{~m} / \mathrm{v})$, que separou por densidade a fração leve e solubilizou a fração ácidos fúlvicos livres (AFL). Em seqüência, sobre a amostra de solo foi colocada a mistura extratora

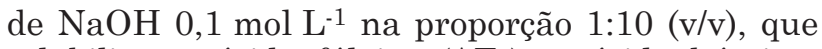
solubilizou os ácidos fúlvicos (AFs) e os ácidos húmicos (AHs). O resíduo sólido insolúvel resultante do processo de fracionamento foi denominado de humina $(\mathrm{H})$. Os AHs foram separados dos AFs por centrifugação (30 min/ $3.500 \mathrm{rpm}$ ) após precipitação em meio ácido obtido com adição de $\mathrm{H}_{2} \mathrm{SO}_{4}$ concentrado até valor de $\mathrm{pH} 1$. O teor de $\mathrm{C}$ em cada fração foi determinado por meio do procedimento Walkley-Black modificado, utilizando calor externo (Embrapa, 1997), com três repetições

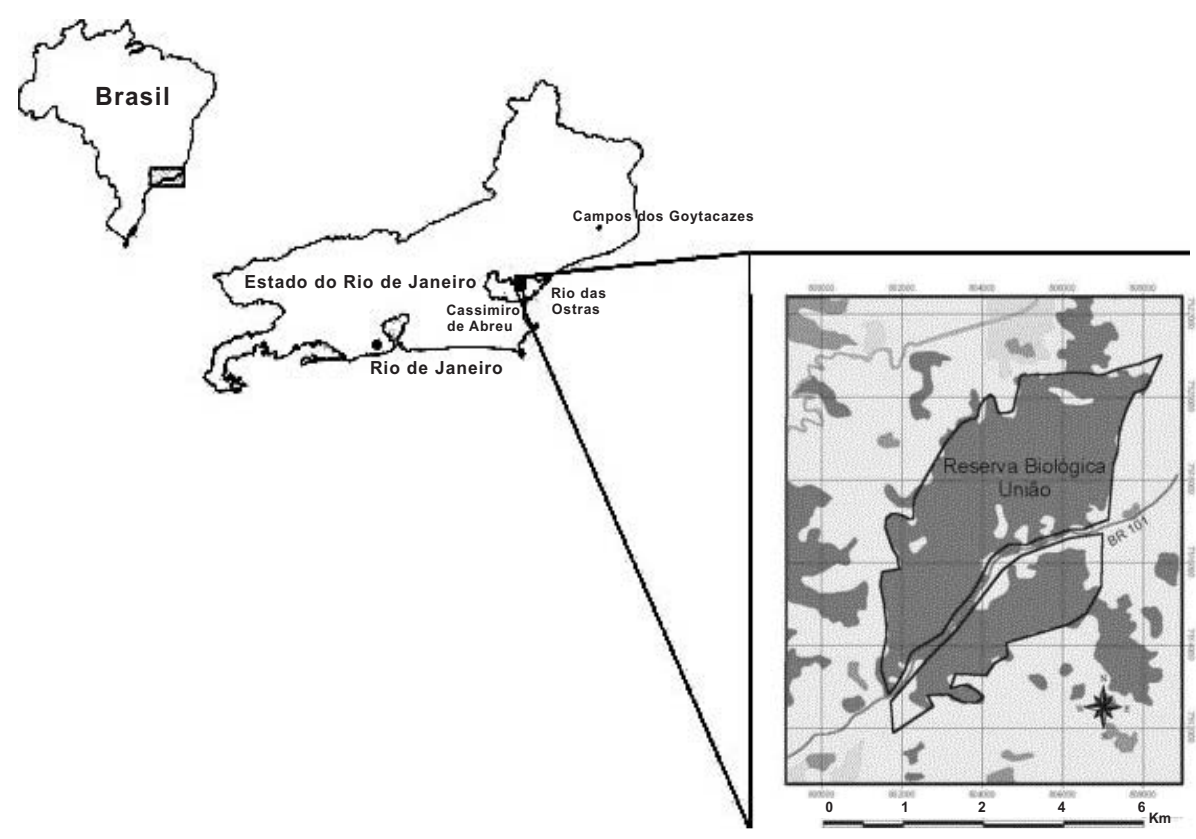

Figura 1. Localização da Reserva Biológica União, em Rio das Ostras - RJ, Brasil. 


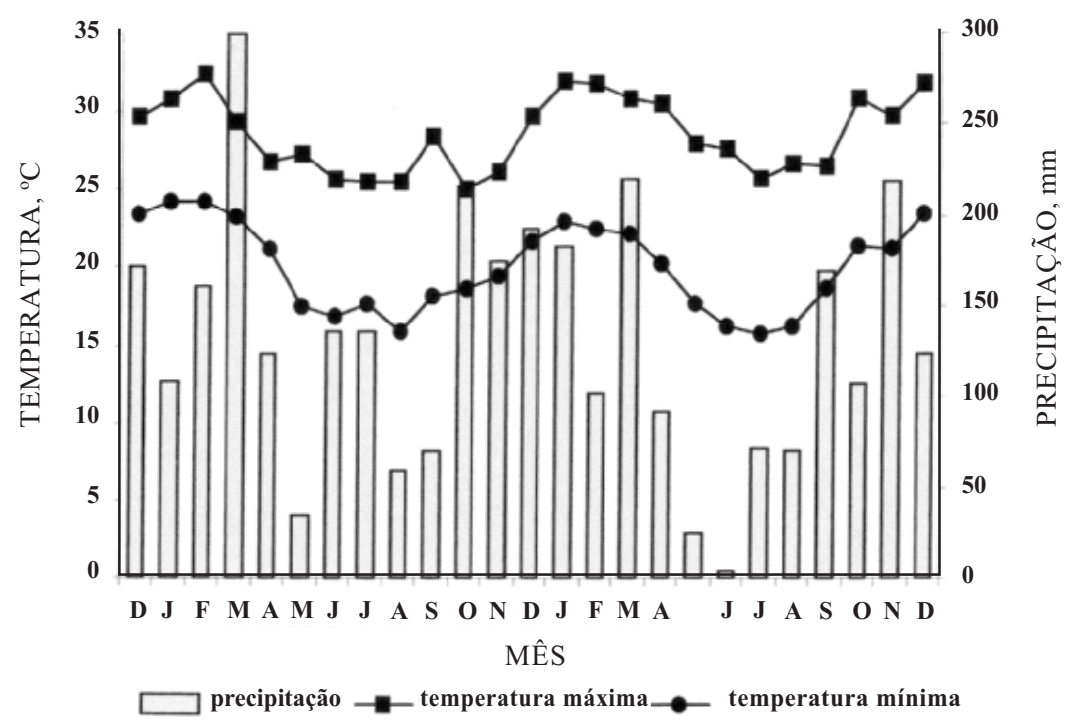

Figura 2. Precipitação pluvial mensal e médias das temperaturas máxima e mínima ocorridas na Reserva Biológica União, no período de dezembro de 1998 a dezembro de 2000 (dados coletados pelo Projeto de Translocação de Micos-Leões - Dourados).

por tratamento, oriundas das três amostras (compostas) de solo. As diferenças estatísticas entre as frações húmicas foram determinadas por meio do delineamento inteiramente casualizado, com os tratamentos A, B, C, D e E. A análise de variância foi realizada pelo teste $\mathrm{F}$ e, quando significativo, as médias foram comparadas pelo teste de Tukey a $5 \%$.

A extração para caracterização dos AHs foi realizada conforme as normas da Sociedade Internacional das Substâncias Húmicas, com prétratamento das amostras com solução de $\mathrm{HCl}$ $0,1 \mathrm{~mol} \mathrm{~L}^{-1}$ e extração com $\mathrm{NaOH} 0,5 \mathrm{~mol} \mathrm{~L}^{-1}$ sob atmosfera de $\mathrm{N}_{2}$ na razão solvente: solo de 10:1 (v/v). Os AHs foram separados por precipitação em meio ácido ( $\mathrm{pH}=1,0-1,5)$ com HCl $6 \mathrm{~mol} \mathrm{~L}-1$. A dissolução dos AHs em meio alcalino e a precipitação em meio ácido foram repetidas três vezes. Em seguida, os AHs foram tratados com $\mathrm{HCl} 0,1 \mathrm{~mol} \mathrm{~L}^{-1}+\mathrm{HF} 0,3 \mathrm{~mol} \mathrm{~L}^{-1}$ durante 12 horas com agitação constante e, após se desprezar o sobrenadante, foram lavados com água até teste negativo com $\mathrm{AgNO}_{3}$. Foram, ainda, dialisados contra água deionizada (membrana $14 \mathrm{Kda}$, Thomas Sci., Inc.) e secos por liofilização. Devido à persistência de altos teores de cinza, as amostras de AHs foram repurificadas mais duas vezes.

A determinação do conteúdo de $\mathrm{C}, \mathrm{H}$ e $\mathrm{N}$ foi realizada por meio de analisador automático $(\mathrm{CHN}$ analyzer Perkin Elmer 1420) em amostras de AHs. $\mathrm{O}$ conteúdo de $\mathrm{O}$ foi obtido de forma indireta, pela diferença do somatório da composição de C, H e N, descontando-se o teor de cinzas obtido a partir da incineração das amostras dos AHs em mufla a $700{ }^{\circ} \mathrm{C}$ durante oito horas. A determinação da acidez total e da acidez carboxílica foi realizada de acordo com o método de Schnitzer \& Gupta (1965). A acidez fenólica foi obtida por diferença entre a acidez total e a carboxílica.

A relação da absorbância em 465 e 665 nm (relação $\mathrm{E}_{4} / \mathrm{E}_{6}$ ) foi realizada em um espectrofotômetro Shimadzu, de acordo com o método de Chen et al. (1977), e a área total sob o espectro de emissão de fluorescência, com excitação em $465 \mathrm{~nm}$, varrendo a faixa de 450 a $650 \mathrm{~nm}$, de acordo com Milori et al. (2002). Foram utilizadas soluções de AHs diluídos (50 mg L-1 de C + solução de $\mathrm{NaHCO}_{3} 0,05 \mathrm{~mol} \mathrm{~L}^{-1}$ ).

$\mathrm{Na}$ espectroscopia no Infravermelho com Transformada de Fourier (IVTF), a faixa espectral analisada foi de 400 a $4.000 \mathrm{~cm}^{-1}$, utilizando-se pastilhas com $1 \mathrm{mg}$ de $\mathrm{AH}$ em $100 \mathrm{mg}$ de $\mathrm{KBr}$, em um aparelho Shimadzu 83000. Foi utilizado o modo de subtração do espectro obtido com a pastilha de $\mathrm{KBr}$ sem utilização da amostra para deduzir a contaminação com $\mathrm{H}_{2} \mathrm{O}$ (região entre 3.300 e $3.400 \mathrm{~cm}^{-1}$ ) e presença de $\mathrm{CO}_{2}$ $\left(2.340 \pm 10 \mathrm{~cm}^{-1}\right)$.

\section{RESULTADOS E DISCUSSÃO}

As amostras de solo apresentaram valores baixos de pH em água, evidenciando acidez elevada nas áreas cobertas tanto por fragmentos de Mata Atlântica quanto por plantios abandonados de eucalipto, apesar de esses valores terem sido menos acentuados nas áreas $\mathrm{C}$ e E (Quadro 1). Em condições de extrema acidez (valores de $\mathrm{pH}$ muito baixos e altos teores de $\mathrm{Al}$ trocável) pode ocorrer limitação na decomposição da MOS e o seu acúmulo (Tomé Jr., 1997). De maneira 
geral, os solos com acidez elevada apresentam baixos teores de cátions trocáveis, o que, segundo Cerri \& Volkoff (1988), implica baixa atividade biológica.

A CTC efetiva encontrada variou de 3,1 a $4,8 \mathrm{cmol}_{\mathrm{c}} \mathrm{kg}^{-1}$ na profundidade de $0-0,10 \mathrm{~m}$ e de $2,7 \mathrm{a}$ 3,1 na de 0,10-0,20 m (Quadro 1). Além da baixa capacidade de troca, o complexo de troca dos solos estudados foi dominado por $\mathrm{Al}^{3+}$, com a saturação deste elemento variando de 68 a $87 \%$ nos fragmentos de mata e na área de plantio abandonado de eucalipto com 16 anos (área D).

Nas áreas de eucalipto (C e E) foi notado o reflexo da calagem anterior ao plantio, de forma que os valores de $\mathrm{pH}$, CTC efetiva e saturação de bases foram mais elevados em relação aos de outras áreas em estudo. Isso foi constatado principalmente na profundidade de 0-0,10 m, onde há maior influência da calagem, ou seja, maior conteúdo de $\mathrm{Ca}^{2+}$ (Quadro 1). No entanto, esses valores ainda são considerados baixos. Além disso, a saturação por $\mathrm{Al}^{3+}$ foi menor (6 a $70 \%$ ) de acordo com o aumento no conteúdo de $\mathrm{Ca}^{2+}$, mas o complexo de troca permaneceu ainda saturado com $\mathrm{H}+\mathrm{Al}$ (Quadro 1). De forma geral, a conseqüência da baixa CTC e da elevada acidez é a baixa percentagem de saturação de bases encontrada nas áreas, indicando a precária fertilidade química do solo em todas as áreas amostradas (Quadro 1).

$\mathrm{O}$ fracionamento da MOS indicou que as $\mathrm{SHs}$ representam menos de $50 \%$ do $\mathrm{C}$ total prontamente oxidável dos solos em estudo, e seu conteúdo diminuiu em profundidade (Quadro 2). A maior parte da MOS analisada é constituída, portanto, pela fração não- humificada, chamada de matéria orgânica leve. As fortes restrições de fertilidade observadas nos solos (Quadro 1) favoreceram o acúmulo de MO pouco transformada em todas as áreas estudadas. Esses resultados estão de acordo com Cerri \& Volkoff (1988), que atribuem a presença de bases como fator primordial no processo de humificação do solo, já que baixos teores de cátions trocáveis implicam baixa atividade biológica.

Na distribuição das frações húmicas, a maior parte do $\mathrm{C}$ humificado foi composta pela fração humina $\left(\mathrm{C}_{\mathrm{H}}\right)$, que representou entre 21 e $29 \%$ e 17 e $27 \%$ do $\mathrm{C}$ total nas profundidades de $0-0,10$ e $0,10-0,20 \mathrm{~m}$, respectivamente (Figura 3). Em outros Argissolos do Rio de Janeiro, submetidos ao cultivo agrícola ou ao pousio, a fração humina constitui normalmente acima de 70 \% do C total (Canellas et al., 2002a,b; 2004). Essa fração humina apresenta natureza química essencialmente alifática, proveniente da preservação seletiva de biopolímeros oriundos de plantas e microrganismos que interagem intimamente com a fração mineral dos solos (Rice, 2001). Outros fatores, como a natureza oxídica da fração mineral e as reações de desidratação favorecidas pela alternância de períodos secos e úmidos, contribuem com a intensificação da formação de humina em solos tropicais (Dabin, 1981).

De acordo com os critérios de interpretação do fracionamento da MOS, adaptados da proposta de Dabin por Canellas et al. (2003), valores menores que $45 \%$ de $\mathrm{C}_{\mathrm{H}}$ representam estádio fraco de humificação da MOS. Assim, apesar de o $\mathrm{C}_{\mathrm{H}}$ ter constituído a maior

Quadro 1. Propriedades químicas e granulometria de um Gleissolo sob mata alagada (A), Cambissolo sob mata de morrote (B) e Argissolo sob plantios abandonados de eucaliptos com 14, 16 e 18 anos (C, D e E, respectivamente), em duas profundidades do perfil do solo

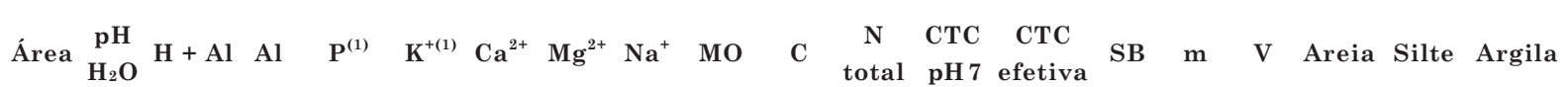

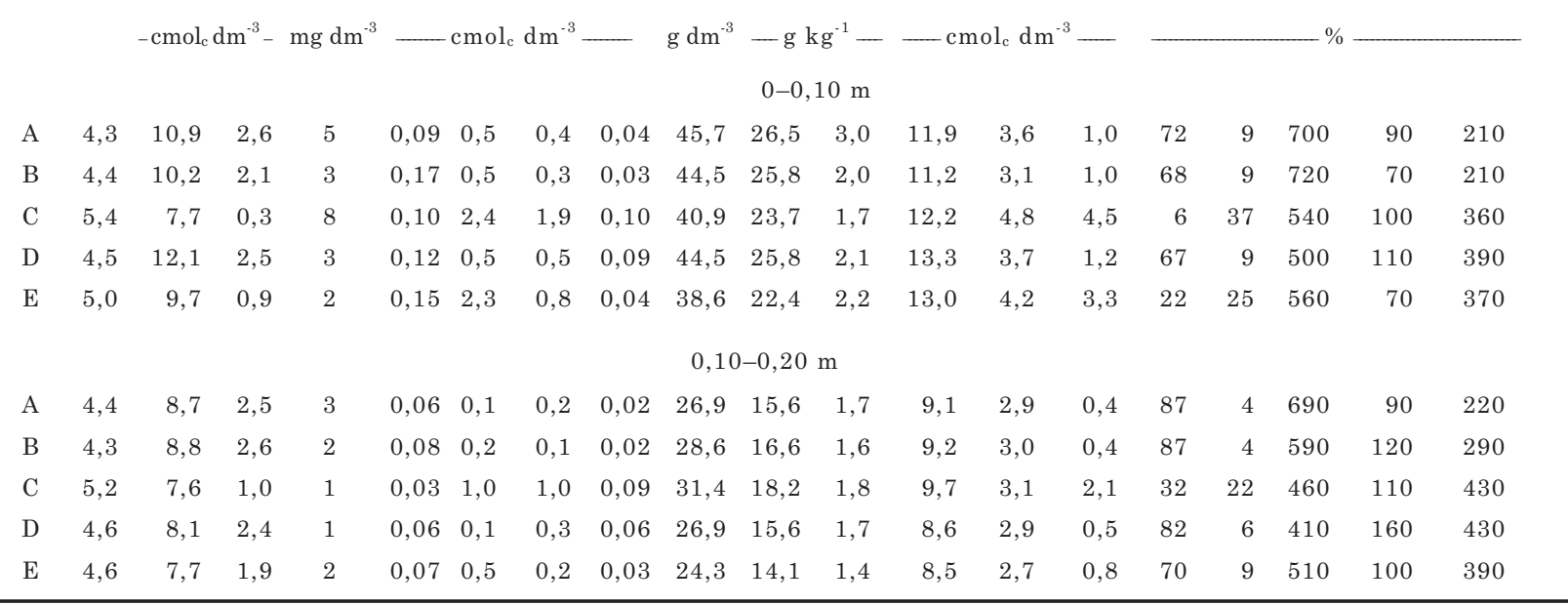

(1) Extrator Carolina do Norte. 
Quadro 2. Diferentes frações da MOS de um Gleissolo sob mata alagada (A), Cambissolo sob mata de morrote (B) e Argissolo sob plantios abandonados de eucaliptos com 14, 16 e 18 anos (C, D e E, respectivamente), em duas profundidades do perfil do solo. Valores entre parênteses representam os erros-padrão das médias

\begin{tabular}{llllllll}
\hline Área & C total & $\mathrm{C}_{\mathrm{SH}}$ & $\mathrm{C}_{\mathrm{AFL}}$ & $\mathrm{C}_{\mathrm{AF}}$ & $\mathrm{C}_{\mathrm{AH}}$ & $\mathrm{C}_{\mathrm{H}}$ & $\mathrm{C}_{\mathrm{AH} / \mathrm{AF}}$ \\
\hline
\end{tabular}

\begin{tabular}{|c|c|c|c|c|c|c|c|}
\hline \multicolumn{8}{|c|}{$0-0,10 \mathrm{~m}$} \\
\hline A & $31,5( \pm 0,2)$ & 11,0 & $0,6( \pm 0,1)$ & $2,0( \pm 0,3)$ & $1,6( \pm 0,2)$ & $6,8( \pm 0,5)$ & 0,6 \\
\hline B & $28,3( \pm 0,4)$ & 11,1 & $0,7( \pm 0,2)$ & $1,9( \pm 0,1)$ & $1,1( \pm 0,1)$ & $7,4( \pm 0,8)$ & 0,4 \\
\hline $\mathrm{C}$ & $27,9( \pm 0,6)$ & 11,5 & $0,5( \pm 0,1)$ & $1,8( \pm 0,3)$ & $1,1( \pm 0,1)$ & $8,1( \pm 0,2)$ & 0,5 \\
\hline $\mathrm{D}$ & $27,6( \pm 2,3)$ & 10,8 & $0,6( \pm 0,1)$ & $1,5( \pm 0,7)$ & $1,2( \pm 0,1)$ & $7,5( \pm 1,1)$ & 0,6 \\
\hline $\mathrm{E}$ & $28,1( \pm 0,9)$ & 11,5 & $0,8( \pm 0,1)$ & $1,9( \pm 0,3)$ & $1,3( \pm 0,2)$ & $7,5( \pm 0,8)$ & 0,5 \\
\hline CV (\%) & 5,6 & 12,7 & 21,8 & 24,1 & 18,5 & 14,0 & 29,0 \\
\hline $\mathrm{F}$ & $2,9^{\mathrm{ns}}$ & $0,2^{\mathrm{ns}}$ & $1,5^{\mathrm{ns}}$ & $0,5^{\mathrm{ns}}$ & $2,4^{\mathrm{ns}}$ & $0,6^{\mathrm{ns}}$ & $1,4^{\mathrm{ns}}$ \\
\hline \multicolumn{8}{|c|}{$0,10-0,20 \mathrm{~m}$} \\
\hline A & $20,7( \pm 3,2)$ & 6,6 & $0,5( \pm 0,1) \mathrm{AB}$ & $1,8( \pm 0,8)$ & $0,8( \pm 0,1)$ & $3,5( \pm 0,7) \mathrm{B}$ & 0,4 \\
\hline $\mathrm{B}$ & $16,6( \pm 0,2)$ & 7,3 & $0,6( \pm 0,1) \mathrm{AB}$ & $1,1( \pm 0,3)$ & $0,7( \pm 0,1)$ & $4,8( \pm 0,2) \mathrm{AB}$ & 0,4 \\
\hline $\mathrm{C}$ & $22,5( \pm 0,7)$ & 8,6 & $0,8( \pm 0,3) \mathrm{A}$ & $1,2( \pm 0,3)$ & $0,5( \pm 0,1)$ & $5,7( \pm 0,3) \mathrm{A}$ & 0,3 \\
\hline $\mathrm{D}$ & $20,2( \pm 0,5)$ & 6,3 & $0,2( \pm 0,1) \mathrm{B}$ & $0,9( \pm 0,2)$ & $0,7( \pm 0,2)$ & $4,6( \pm 0,3) \mathrm{AB}$ & 0,6 \\
\hline $\mathrm{E}$ & $20,8( \pm 1,0)$ & 6,4 & $0,7( \pm 0,1) \mathrm{A}$ & $1,2( \pm 0,4)$ & $0,7( \pm 0,2)$ & $3,8( \pm 0,6) \mathrm{AB}$ & 0,4 \\
\hline CV (\%) & 11,3 & 14,4 & 36,4 & 45,8 & 27,1 & 14,9 & 34,9 \\
\hline $\mathrm{F}$ & $2,4 \mathrm{~ns}$ & $9,2 \mathrm{~ns}$ & 4,9 & $1,2^{\mathrm{ns}}$ & $0,8 \mathrm{~ns}$ & 10,8 & $0,4^{\mathrm{ns}}$ \\
\hline
\end{tabular}

Médias nas colunas seguidas por letras diferentes, em cada profundidade, diferem entre si pelo teste de Tukey $(\mathrm{P}<0,05) .{ }^{\text {ns }}$ Nãosignificativo. Ctotal= carbono prontamente oxidável da MOS; $\mathrm{C}_{\mathrm{SH}}, \mathrm{C}_{\mathrm{AFL}}, \mathrm{C}_{\mathrm{AF}}, \mathrm{C}_{\mathrm{AH}}$ e $\mathrm{C}_{\mathrm{H}}$ representam os teores de carbono contido nas substâncias húmicas e em suas frações: ácidos fúlvicos livres, ácidos fúlvicos, ácidos húmicos e huminas, respectivamente.

parte do C humificado, sua percentagem foi baixa em relação ao $\mathrm{C}$ total refletindo características de húmus pouco evoluído, típico de ambientes com fortes restrições à atividade microbiana.

$\mathrm{O}$ conteúdo de $\mathrm{C}$ na fração humina $\left(\mathrm{C}_{\mathrm{H}}\right)$ variou de 6,8 a $8,1 \mathrm{~g} \mathrm{~kg}^{-1}$ na profundidade de $0-0,10 \mathrm{~m}$, não sendo observadas diferenças significativas em função da cobertura vegetal (Quadro 2). Em subsuperfície, na área de Mata Atlântica que sofreu hidromorfismo periódico, foi observado o menor conteúdo de $\mathrm{C}_{\mathrm{H}}\left(3,5 \mathrm{~g} \mathrm{~kg}^{-1}\right)$.

Conforme Dabin (1981), a evolução do húmus pode ser modificada pelo hidromorfismo. Nesses ambientes, a via de herança (evolução direta dos compostos insolúveis lignificados da MO pouco transformada) é o processo de humificação predominante (Camargo et al., 1999), pois as outras vias de humificação, como a de insolubilização (humificação dos compostos fenólicos solúveis) e neo-síntese microbiana (humificação das moléculas simples através da síntese microbiana), necessitam de elevada pressão de $\mathrm{O}_{2}$ para manter a atividade da microbiota do solo. Dessa forma, o alagamento periódico dos solos da área A torna este tipo de ambiente pobre em oxigênio, dificultando a atividade biológica e, por conseqüência, o processo de mineralização e humificação da MOS.
Poucas diferenças foram observadas no conteúdo de $\mathrm{C}$ nas frações humificadas alcalino-solúveis. $\mathrm{O}$ conteúdo de $\mathrm{C}_{\mathrm{AH}}$ variou de 1,1 a 1,6 e de 0,5 a $0,8 \mathrm{~g} \mathrm{~kg}^{-1}$ nas profundidades de $0-0,10$ e $0,10-0,20 \mathrm{~m}$. O conteúdo de $\mathrm{C}_{\mathrm{AFL}}$ oscilou de 0,5 a 0,8 e 0,2 a $0,8 \mathrm{~g} \mathrm{~kg}^{-1}$ nas camadas superficiais e subsuperficiais, respectivamente. Já os valores de $\mathrm{C}_{\mathrm{AF}}$ variaram de 1,5 a 2,0 e 0,9 a $1,8 \mathrm{~g} \mathrm{~kg}^{-1}$ nas respectivas camadas do solo citadas anteriormente (Quadro 2). Provavelmente, as restrições impostas pela baixa fertilidade do solo justificam a pouca evolução da matéria orgânica humificada solúvel, contribuindo para obtenção de valores próximos, independentemente da cobertura vegetal.

$\mathrm{O}$ conteúdo de $\mathrm{C}_{\mathrm{AHs}}$ dos solos estudados foi menor do que o das frações fúlvicas $\left(\mathrm{C}_{\mathrm{AF}}+\mathrm{C}_{\mathrm{AFL}}\right)$, conferindo valores menores que 1 para a razão $\mathrm{C}_{\mathrm{AH}} / \mathrm{C}_{\mathrm{AF}}$. Esta razão foi usada por Kononova (1982) como indicador da qualidade do húmus, pois expressa o grau de evolução do processo de humificação da matéria orgânica. Em solos tropicais, normalmente, essa razão é inferior a 1 devido à menor intensidade do processo de humificação, ou seja, condensação e síntese, atribuídas à intensa mineralização dos resíduos, às restrições edáficas e ao baixo conteúdo de bases trocáveis, restringindo a atividade biológica nos solos mais intemperizados (Canellas et al., 2002b). 


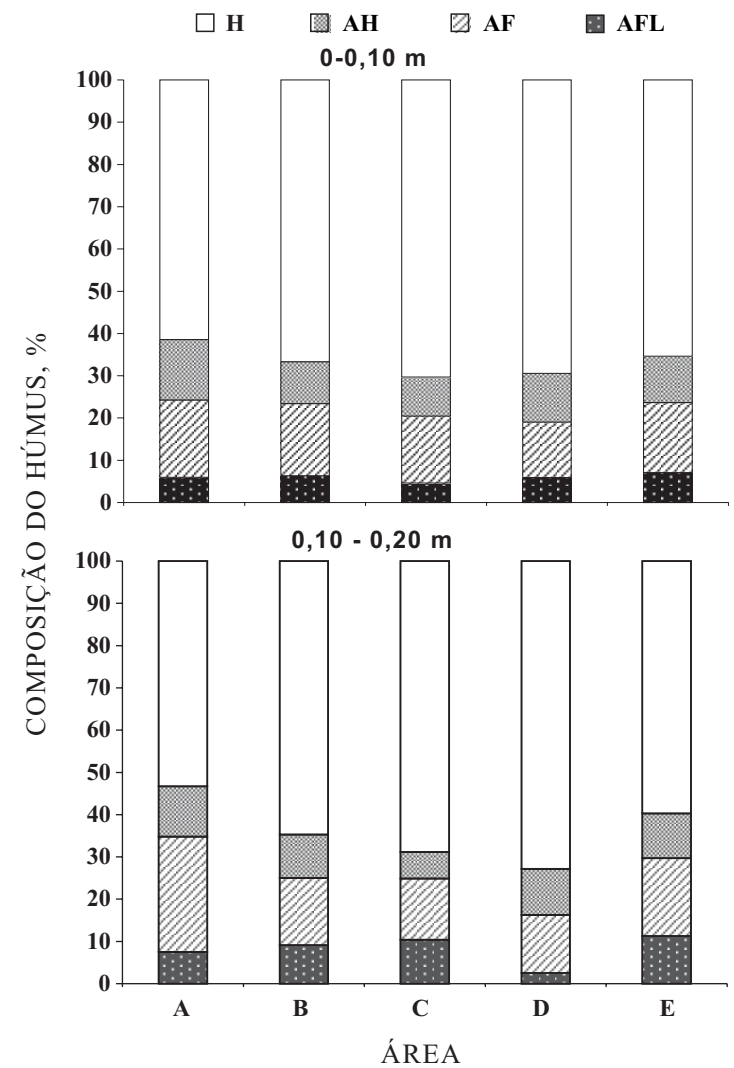

Figura 3. Distribuição percentual do carbono das frações húmicas obtidas no fracionamento químico de um Gleissolo sob mata alagada (A); Cambissolo sob mata de morrote (B); e Argissolo sob plantios abandonados de eucalipto com 14, 16 e 18 anos (C, D, E, respectivamente), em duas profundidades: $100 \%=\mathrm{C}_{\mathrm{AFL}}+\mathrm{C}_{\mathrm{AF}}+\mathrm{C}_{\mathrm{AH}}+\mathrm{C}_{\mathrm{H}}$. $\mathrm{C}_{\mathrm{AFL}}, \mathrm{C}_{\mathrm{AF}}, \mathrm{C}_{\mathrm{AH}}$ e $\mathrm{C}_{\mathrm{H}}$ representam os teores de carbono contido nas frações ácidos fúlvicos livres (AFL), ácidos fúlvicos (AF), ácidos húmicos (AH) e huminas $(\mathrm{H})$, respectivamente.

Foi observado baixo acúmulo de SHs alcalinosolúveis mais condensadas (AH) e insolúveis (humina) na camada superficial, em relação à subsuperficial. As frações humificadas altamente solúveis, como AFL e AF, apresentam, em razão do seu elevado conteúdo de grupamentos funcionais polares, alta capacidade de solvatação, sendo arrastadas pela água de percolação do solo. $\mathrm{O}$ conteúdo de $\mathrm{C}_{\mathrm{AFL}}$ e $\mathrm{C}_{\mathrm{AF}}$ foi similar, independentemente da profundidade do solo (Quadro 2).

Os resultados da composição elementar dos $\mathrm{AHs}$ estão apresentados no quadro 3 . O conteúdo de $\mathrm{C}$ observado para os AHs isolados nas diferentes áreas variou de 344 a $464 \mathrm{~g} \mathrm{~kg}^{-1}$, diminuindo com a profundidade do solo - considerado relativamente baixo. Os valores normalmente encontrados para o conteúdo de $\mathrm{C}$ em AHs estão na faixa de 538 a $587 \mathrm{~g} \mathrm{~kg}^{-1}$ (Stevenson, 1994). Esses resultados sugerem que houve baixa taxa de condensação da fração húmica, que pode ser atribuída à predominância de "óxidos", normalmente encontrados em solos tropicais, onde as cargas positivas superficiais dos colóides disputam os sítios de carga negativa da matéria orgânica no processo de humificação, interrompendo, pelo menos em parte, a evolução química dos compostos húmicos.

Além disso, os valores de $\mathrm{pH}$ da solução de solos tropicais com elevado grau de intemperização, como os observados neste estudo (Quadro 1), não permitem que ocorra a ionização de polieletrólitos de ácidos fracos da matéria orgânica humificada. Dessa forma, a superfície orgânica provavelmente permanece, na sua maior parte, saturada com $\mathrm{H}^{+}$, impedindo a interação com metais livres da solução do solo e a sua policondensação catalisada pelos metais polivalentes.

Os valores obtidos para hidrogênio $(\mathrm{H})$ e nitrogênio (N) variaram entre 52 e 72 e 27 e $45 \mathrm{~g} \mathrm{~kg}^{-1}$, respectivamente (Quadro 3). Faixas normalmente encontradas para o conteúdo de $\mathrm{H}$ são de 32 a $62 \mathrm{~g} \mathrm{~kg}^{-1}$ e, para $\mathrm{N}$, de 8 a $43 \mathrm{~g} \mathrm{~kg}^{-1}$ (Stevenson, 1994). O aumento do conteúdo de $\mathrm{N}$ na fração $\mathrm{SH}$ s é um indicador bastante utilizado para avaliar o grau de humificação, uma vez que a condensação de moléculas parcialmente humificadas é mediada, em parte, pela ação de grupamentos amino (Kononova, 1982). Se, por um lado, a natureza oxídica da fração mineral interrompe o processo de humificação e formação de macromoléculas húmicas, por outro, a natureza ácida dos $\mathrm{AHs}$ com predomínio de grupamentos fenólicos favorece a precipitação de $\mathrm{N}$ em solução, imobilizando e tornando-o indisponível aos microrganismos e às reações de condensação. A interação de polifenóis com $\mathrm{N}$ é bastante conhecida. A incorporação de $\mathrm{N}$ via precipitação com grupamentos $\mathrm{OH}$-fenólicos pode ser justificada pela elevada presença destes compostos em todos os AHs estudados.

Os conteúdos de $\mathrm{H}$ nas frações $\mathrm{AHs}$ foram semelhantes para as diferentes coberturas vegetais nas duas profundidades dos solos estudados (Quadro 3).

$\mathrm{O}$ valores de oxigênio $(\mathrm{O})$ nos $\mathrm{AHs}$ variaram de 432 a $562 \mathrm{~g} \mathrm{~kg}^{-1}$, faixa normalmente observada para material humificado menos condensado (AFs observados por Stevenson, 1994), o que implica AHs bastante oxidados e menor intensidade no processo de humificação. Além disso, o alto conteúdo de cinzas obtido nesses AHs (Quadro 3), mesmo depois do tratamento com ácido fluorídrico, que destrói minerais de argila silicatados, mas ataca menos os óxidos de $\mathrm{Fe}$ e Al, pode indicar que esses minerais interagiram com o material húmico e bloquearam seus sítios de reação, que, por sua vez, impediram a condensação dos AHs.

A partir da composição elementar dos AHs são obtidas as razões atômicas $\mathrm{C} / \mathrm{N}, \mathrm{H} / \mathrm{C} \mathrm{e} \mathrm{O} / \mathrm{C}$, que podem ser usadas para analisar o comportamento químico dos AHs (Lu et al., 2000). Com exceção dos AHs isolados na área de regeneração por 14 anos (C), os valores encontrados para razão $\mathrm{C} / \mathrm{N}$ foram baixos 
Quadro 3. Composição elementar, razão atômica (livres de cinzas e umidade) e percentagem de cinzas dos ácidos húmicos (AHs) extraídos de um Gleissolo sob mata alagada (A), Cambissolo sob mata de morrote (B) e Argissolo sob plantios abandonados de eucaliptos com 14, 16 e 18 anos (C, D, E, respectivamente), coletados nas camadas de $0-0,10$ e $0,10-0,20 \mathrm{~m}$ de profundidade no solo

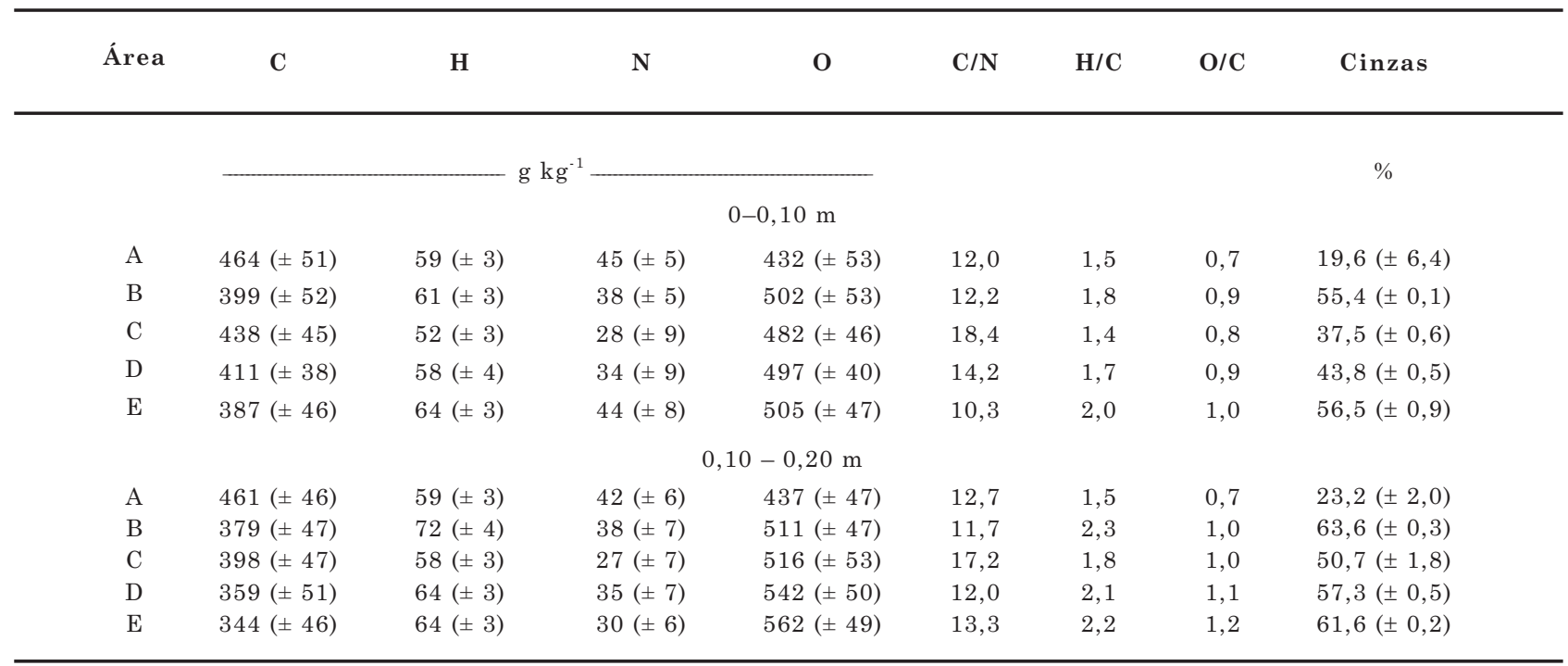

C: carbono; H: hidrogênio; N: nitrogênio; O: oxigênio. Valores entre parênteses representam os erros-padrão das médias.

(Quadro 3), oscilando entre 10 e 14 e indicando material humificado disponível ao ataque biológico. Vilella et al. (2004) verificaram que o conteúdo de N, na serrapilheira proveniente da mesma área estudada, foi a metade do observado nas outras áreas de eucalipto e em uma mata nativa adjacente na mesma Reserva Biológica. O valor de N na amostra de solo (Quadro 1), na camada superficial da área $\mathrm{C}$, também foi menor em relação às demais áreas, porém o comportamento não foi o mesmo em subsuperfície. É possível, então, estabelecer uma concepção teórica ou modelo para humificação da matéria orgânica desta área, que é dependente da atividade biológica e dos produtos dessa atividade na serrapilheira mais do que na fração mineral do solo. O fluxo de nutrientes, provenientes da ciclagem da matéria orgânica presente na serrapilheira, onde as raízes são superficialmente dispostas para aproveitar os nutrientes, é bastante compartimentado, com pouca interferência da capacidade de troca de cátions do solo. Dessa forma, áreas que apresentaram serrapilheira com baixo conteúdo de nutrientes produziram $\mathrm{SHs}$ com menor conteúdo de $\mathrm{N}$.

A razão $\mathrm{H} / \mathrm{C}$ tem sido usada por muitos pesquisadores como indicador indireto do grau de aromaticidade ou de insaturação das $\mathrm{SH}_{\mathrm{s}}$ (Rice \& MacCarthy, 1991). Os valores dessa razão variaram de 1,4 a 2,0 nos AHs isolados na profundidade de $0-0,10 \mathrm{~m}$ e de 1,5 a 2,2 na camada de $0,10-0,20 \mathrm{~m}$ do solo (Quadro 3). Normalmente, em AHs de clima temperado, a razão $\mathrm{H} / \mathrm{C}$ é menor que 1 , indicando a presença de compostos orgânicos bastante substituídos e com grau mais elevado de conjugação. Neste estudo, a natureza alifática do material húmico foi bastante evidente (os valores da razão $\mathrm{H} / \mathrm{C}$ sempre foram acima de 1), indicando também a presença de material com característica apolar nos $\mathrm{AHs}$, típicos de $\mathrm{SHs}$ pouco evoluídas estruturalmente. Com a profundidade, a razão $\mathrm{H} / \mathrm{C}$ tendeu a aumentar, sugerindo diminuição do grau de humificação dos $\mathrm{AHs}$, ou seja, quanto menor a atividade biológica, que aumenta a síntese do material húmico, e com menor $\mathrm{pH}$ e conteúdo de bases, na profundidade de $0,10-0,20 \mathrm{~m}$, é provável que tenha ocorrido diminuição das reações de substituição e preservação seletiva de compostos orgânicos alifáticos associados nos AHs.

De acordo com Lu et al. (2000), valores mais altos de $\mathrm{O} / \mathrm{C}$ indicam AHs mais oxidados e com menor grau de condensação. As razões $\mathrm{O} / \mathrm{C}$ obtidas nos $\mathrm{AHs}$ deste estudo foram relativamente elevadas $(0,7-1,2)$, independentemente da cobertura vegetal e profundidade do solo (Quadro 3), aproximando-se dos valores observados para AFs, que, juntamente com a elevada acidez total, carboxílica e fenólica, evidenciam características fulváticas aos AHs (Quadro 4).

A faixa de acidez total, normalmente observada para $\mathrm{AHs}$, varia de 560 a $890 \mathrm{cmol}_{\mathrm{c}} \mathrm{kg}^{-1}$ (Stevenson, 1994; Barancíková et al., 1997; Senesi et al., 2003). Já no presente estudo, os resultados obtidos para os $\mathrm{AHs}$ foram similares aos valores tipicamente observados para AFs. A acidez total dos $\mathrm{AHs}$ diminuiu em profundidade, o que indica menor reatividade deles com o aumento da profundidade do solo.

Os valores encontrados para acidez total foram próximos aos obtidos para AHs isolados de Argissolos 
Quadro 4. Acidez total, carboxílica e fenólica, razão $\mathrm{E}_{4} / \mathrm{E}_{6}$ e área do espectro de fluorescência de emissão com excitação em $465 \mathrm{~nm}\left(\mathrm{~A}_{465}\right)$ dos AHs extraídos de um Gleissolo sob mata alagada (A), Cambissolo sob mata de morrote (B), e Argissolo sob plantios abandonados de eucaliptos com 14, 16 e 18 anos (C, D, E, respectivamente), em duas profundidades

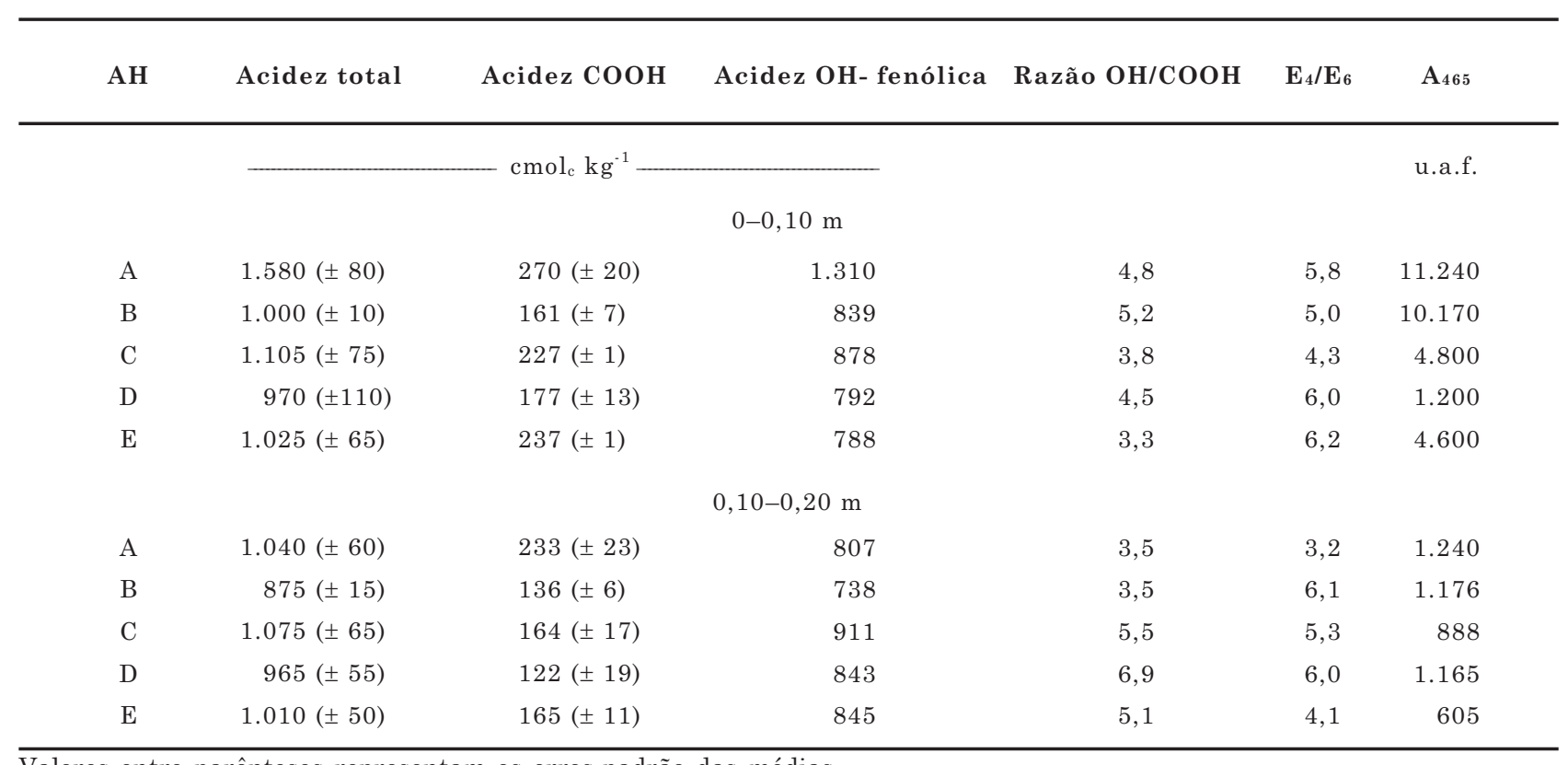

Valores entre parênteses representam os erros-padrão das médias.

da região norte do Estado do Rio de Janeiro (Canellas et al., 2002a,b), onde se observaram valores de acidez total entre 1.030 e $1.627 \mathrm{cmol}_{\mathrm{c}} \mathrm{kg}^{-1} \mathrm{em} \mathrm{AHs}$, sugerindo baixo grau de evolução desses compostos nesses solos tropicais mais intemperizados. A presença de material humificado com acidez elevada tem aspecto importante nos ecossistemas tropicais. A ciclagem de nutrientes ocorre basicamente na camada de serrapilheira, de onde a flora e os microrganismos retiram os íons necessários para o seu crescimento. A presença de grande quantidade de $\mathrm{H}^{+}$, capazes de realizar reações de troca, funciona como uma rede protetora contra a perda de íons por lixiviação e, principalmente, para atenuar, através da complexação, os efeitos deletérios provocados pela presença de quantidade elevada de $\mathrm{Al}^{3+}$ trocável (Quadro 1).

A maior parte da acidez total ocorreu devido à contribuição da acidez fenólica, que foi evidenciada pela elevada razão entre acidez fenólica e carboxílica (OH/COOH), variando entre 3,3 e 6,9 (Quadro 4). De acordo com Rossel et al. (1989), ocorre diminuição no conteúdo de grupos $\mathrm{OH}$ fenólicos e aumento no conteúdo de $\mathrm{COOH}$ com a humificação da MOS, indicando a presença de material húmico pouco evoluído.

A razão $\mathrm{E}_{4} / \mathrm{E}_{6}$ não apresentou relação com o aumento da profundidade e não mostrou nenhuma correlação significativa com os conteúdos de $\mathrm{O}, \mathrm{C}$, $\mathrm{COOH}$ e acidez total (Quadro 4), diferentemente do que foi constatado por Chen et al. (1977). De forma que para a distinção de AHs originados de condições edáficas bastante semelhantes, o uso da razão $\mathrm{E}_{4} / \mathrm{E}_{6}$ pode não ser efetivo, como o observado neste estudo.

Já as análises da espectroscopia de fluorescência demonstraram maior absorção dos AHs dos solos de mata alagada (A) e mata de morrote (B), em relação às áreas de eucalipto (Quadro 4). Isso foi observado nas duas profundidades analisadas, e a intensidade de fluorescência diminuiu consideravelmente na camada de 0,10-0,20 m do solo. De acordo com Pérez et al. (2004), a elevada intensidade de fluorescência está diretamente relacionada com o aumento do grau de aromaticidade e da concentração de radicais livres do tipo semiquinonas, que, por sua vez, indicam maior grau de humificação. É possível indicar então que, para ambientes similares, a técnica de fluorescência apresenta sensibilidade suficiente para discriminar os efeitos da serrapilheira nas características eletrônicas do material humificado. De acordo com Sierra \& Giovanela (1995) e Chen et al. (2003), as propriedades de fluorescência das SHs são dependentes de diversos fatores, como sua origem, massa molar, concentração, $\mathrm{pH}$, força iônica, temperatura, potencial redox do meio, grau de conjugação e efeitos de substituintes. Além disso, a interação com íons metais reduz a intensidade de fluorescência (Ghosh \& Schnizer, 1981).

$\mathrm{Na}$ figura 4 estão apresentados os espectros na região do infravermelho (IV) dos $\mathrm{AHs}$ extraídos dos 
diferentes solos. Na faixa de 3.378 a $3.400 \mathrm{~cm}^{-1}$, foram observadas bandas de absorção alargadas nos AHs, exceto para as áreas B e D, na profundidade de 00,10 m. Essa região é característica da absorção da vibração de estiramento de grupos $\mathrm{OH}$ em pontes de $\mathrm{H}$ inter e intramoleculares. O tamanho do alargamento da absorção tem correspondência com a força da interação $\mathrm{H}$, uma vez que, quanto mais forte a ponte de $\mathrm{H}$, mais energia é necessária para estirar as ligações, proporcionando o alargamento da absorção. As bandas de absorção na região de 3.133 a $3.155 \mathrm{~cm}^{-1}$ podem ser atribuídas à presença de $\mathrm{C}-\mathrm{H}$ aromáticos e ciclos alcanos. Essa absorção está nos AHs da mata alagada (A) e diminui com a profundidade do solo. Em todos os espectros foram observadas absorções na faixa de 2.918 a $2.930 \mathrm{~cm}^{-1}$, atribuídas normalmente à presença de grupos metilas (estiramento $\mathrm{C}-\mathrm{H}$ de grupos $\mathrm{CH}_{3}$ ), o que confirma a presença de estruturas alifáticas observadas pela elevada relação $\mathrm{H} / \mathrm{C}$.

Na região de $1.700 \mathrm{~cm}^{-1}$, característica da absorção de carbonilas de cetonas, foram observadas bandas de absorção em $1.706 \mathrm{~cm}^{-1}$ para AHs da superfície da área A e da maior profundidade da área C; em $1.709 \mathrm{~cm}^{-1}$, para AHs da área E (0,10-0,20 m); e em $1.711 \mathrm{~cm}^{-1}$, para área $\mathrm{C}(0,10-0,20 \mathrm{~m})$, que correspondem a $\mathrm{C}=\mathrm{O}$ de cetonas e grupos COOH. Esses sinais de absorção são mais evidentes nos $\mathrm{AHs}$ da área de eucalipto $\mathrm{C}$ (Figura 4).

As bandas de absorção atribuídas à presença de grupamentos fenólicos normalmente são encontradas na região entre 1.290 e $1.350 \mathrm{~cm}^{-1}$. Foram observadas bandas de absorção nos AHs isolados da camada superficial em $1.393 \mathrm{~cm}^{-1}$ nas áreas $\mathrm{A}$ e $\mathrm{B}$, em $1.383 \mathrm{~cm}^{-1}$ na área $\mathrm{D}$ e em $1.391 \mathrm{~cm}^{-1}$ nas áreas C e E (Figura 4). Com a profundidade, apenas a área A $\left(1.400 \mathrm{~cm}^{-1}\right)$ se diferenciou das demais. Essas absorções são mais fortes que as atribuídas aos grupamentos $\mathrm{COOH}\left(1.239-1.254 \mathrm{~cm}^{-1}\right)$, que apresentaram absorção na mesma região para os AHs das matas apenas na profundidade de $0-0,10 \mathrm{~m}\left(1.393 \mathrm{~cm}^{-1}\right)$. Isso confirma a elevada acidez fenólica observada nas análises dos grupamentos funcionais dos AHs (Quadro 4).

Segundo Garcès (1987), absorção próxima a $1.100 \mathrm{~cm}^{-1}$ é atribuída à presença de grupos COOligados a cátions metálicos. A presença de conteúdo elevado de cinza (Quadro 3) sugere a existência de material inorgânico persistente mesmo após a

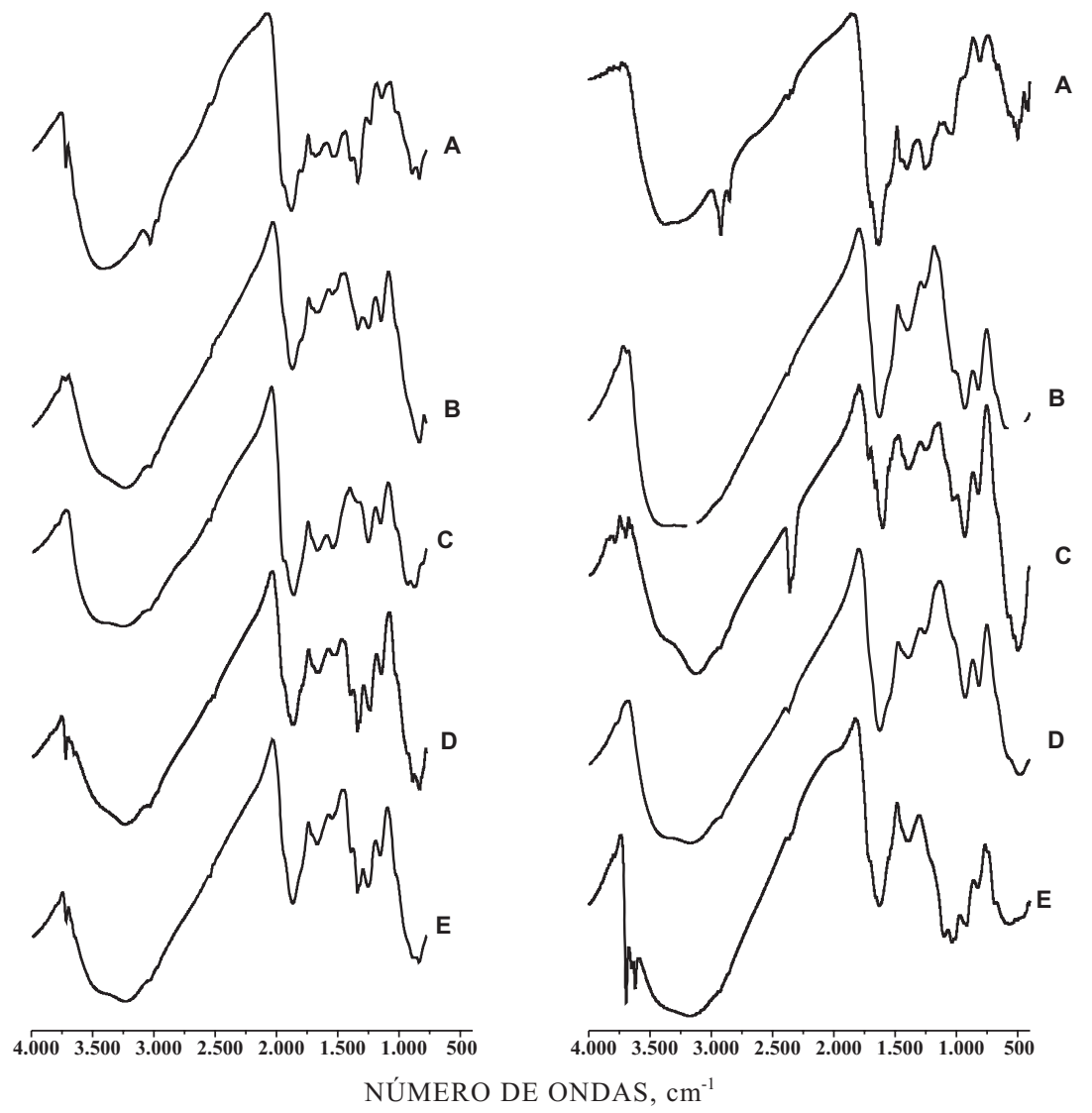

Figura 4. Espectros de infravermelho de AHs extraídos de um Gleissolo sob mata alagada (A); Cambissolo sob mata de morrote (B); e Argissolo sob plantios abandonados de eucaliptos com 14, 16 e 18 anos (C, D, $\mathrm{E}$, respectivamente), em duas profundidades. 
purificação dos AHs, como já observado por Canellas (1999), analisando a capacidade de adsorção de íons metálicos das SHs.

Para a região de absorção correspondente à de formação de $\mathrm{CH}$ aromático $\left(811-935 \mathrm{~cm}^{-1}\right)$, as absorções foram distintas entre os diferentes tipos de $\mathrm{AHs}$. O mesmo foi observado para as absorções na região de 515 a $539 \mathrm{~cm}^{-1}$ (Figura 4).

A região de 1.420 a $910 \mathrm{~cm}^{-1}$, conhecida como impressão digital, corresponde à faixa de absorção dos grupamentos funcionais pouco afetados pelo restante da molécula, sendo, portanto, uma região característica de cada espectro de $\mathrm{AH}$. Os AHs extraídos dos solos apresentaram diferenças na região e na intensidade das bandas de absorção. Os espectros de IV mostraram a presença de estruturas aromáticas e alifáticas, amidas, $\mathrm{COOH}, \mathrm{OH}$ fenólico, além de carboidratos, nesses AHs. Esses dados demonstraram AHs com funcionalidade similar, mas com absorções específicas na região de impressão digital, indicando que há efeito do tipo de solo e da vegetação de cobertura na assinatura química dos $\mathrm{AHs}$, mas não na sua reatividade geral.

\section{CONCLUSÕES}

1. As fortes restrições de fertilidade observadas nos solos favoreceram o acúmulo de matéria orgânica pouco transformada em todas as áreas estudadas.

2. A distribuição relativa das frações que compõem a matéria orgânica humificada não foi alterada pela cobertura vegetal nem pela classe de solo. Os ácidos húmicos apresentaram natureza química semelhante à normalmente encontrada nos ácidos fúlvicos, caracterizando material humificado pouco condensado.

3. A análise de infravermelho permitiu identificar diferenças na estrutura dos ácidos húmicos; apesar da funcionalidade similar, indicou-se a presença de efeito do tipo de solo e da cobertura de vegetação na assinatura química dessa fração húmica.

4. Os materiais humificados isolados dos dois fragmentos de Mata Atlântica apresentaram maior intensidade de fluorescência, possivelmente devido à presença de ligações hidrofóbicas mais fracas, sugerindo maior labilidade e capacidade de ceder elétrons para reações químicas do solo.

\section{AGRADECIMENTOS}

Aos doutores Jolimar A. Schiavo e Marihus A. Baldoto, do CCTA/UENF, pela classificação dos solos. Aos técnicos de campo do Laboratório de Ciências Ambientais/UENF e às técnicas do Laboratório de
Solos do CCTA/UENF. À equipe da Reserva Biológica União/IBAMA. Ao $\mathrm{CNP}_{\mathrm{q}}$, pelo apoio financeiro.

\section{LITERATURA CITADA}

BARANCIKOVÁ, G.; SENESI, N. \& BRUNETTI, G. Chemical and spectroscopic acids isolated from different Slovak soil types. Geoderma, 78:251-266, 1997.

CAMARGO, F.A.O.; SANTOS, G.A. \& GUERRA, J.G.M. Macromoléculas e substâncias húmicas. In: SANTOS, G.A. \& CAMARGO, F.A.O., eds. Fundamentos da matéria orgânica do solo. Porto Alegre, Genesis, 1999. p.27-39.

CANELLAS, L.P. Avaliação de características físico-químicas de ácidos húmicos. Seropédica, Universidade Federal Rural do Rio de Janeiro, 1999. 164p. (Tese de Doutorado)

CANELLAS, L.P.; OLIVARES, F.L. \& OKOROKOVAFAÇANHA, A.L. \& FAÇANHA, A.R. Humic acids isolated from earthworm compost enhance root elongation, lateral root emergence, and plasma membrane $\mathrm{H}^{+}$- ATPase activity in maize roots. Plant Physiol., 130:1951-1957, 2002a.

CANELLAS, L.P.; VELLOSO, A.C.X.; RUMJANEK, V.M.; GURIDI, F.; OLIVARES, F.L.; SANTOS, G.A. \& BRAZFILHO, R. Distribuition of the humified fractions and characteristics of the humic acids of an ultisol under cultivation of Eucalyptus and sugar cane. Terra, 20:371381, 2002b.

CANELLAS, L.P.; VELLOSO, A.C.X.; MARCIANO, C.R.; RAMALHO, J.F.G.P.; RUMJANEK, V.M.; REZENDE, C.E. \& SANTOS, G.A. Propriedades químicas de um Cambissolo cultivado com cana-de-açúcar, com preservação do palhiço e adição de vinhaça por longo tempo. R. bras. Ci. Solo, 27:935-944, 2003.

CANELLAS, L.P.; ESPINDOLA, A.J.A.; RESENDE, C.E.; CAMARGO, P.B.; ZANDONADI, D.B.; RUMJANEK, V.M.; GUERRA, J.G.M.; TEIXEIRA, M.G. \& BRAZ-FILHO, R. Organic matter quality in a soil cultivated with perennial herbaceous legumes. Sci. Agric., 61:53-61, 2004.

CERRI, C.C. \& VOLKOFF, B. Matéria orgânica de três solos dos campos inundáveis da Ilha de Marajó/PA. R. Bras. Ci. Solo, 12:93-100, 1988.

CHEN, J.; LEBOEUF, E.J.; DAI, S. \& GU, B. Fluorescence spectroscopic studies of natural organic matter fractions. Chemosphere, 50:639-647, 2003.

CHEN, Y.; SENESI, N. \& SCHNITZER, M. Information provided on humic substances by $\mathrm{E}_{4} / \mathrm{E}_{6}$ Ration. Soil Sci. Soc. Am. J., 41:352-358, 1977.

DABIN, B. Les matières organiques dans les sols tropicaux normalement drainès. Cah. O.R.S.T.O.M., Sér. Pédol., 18:197-215, 1981.

EMPRESA BRASILEIRA DE PESQUISA AGROPECUÁRIA EMBRAPA. Centro Nacional de Pesquisa de Solos. Manual de métodos de análise de solo. 2.ed. Rio de Janeiro, 1997. $212 p$. 
EMPRESA BRASILEIRA DE PESQUISA AGROPECUÁRIA EMBRAPA. Centro Nacional de Pesquisa de Solos. Sistema brasileiro de classificação de solos. Rio de Janeiro, 1999. $412 \mathrm{p}$

GARCÈS, G.P. Características actuales del humus en los principales tipos de suelos de Cuba. Nitra, Universidad de Agricultura de Nitra, 1987. 200p. (Tese de Doutorado)

GHOSH, K. \& SCHNITZER, M. Fluorescence excitation spectra and viscosity behavior of a fuvic acid and its copper and iron complexes. Soil Soc. Am., 45:25-29,1981.

GUERRA, J.G.M. \& SANTOS, G.A. Métodos químicos e físicos. In: SANTOS, G.A. \& CAMARGO F.A.O., eds. Fundamentos da matéria orgânica do solo. Porto Alegre, Genesis, 1999. p.267-291

KONONOVA, M.M. Matéria orgânica del suelo; su natureza, propriedades y métodos de investigación. Barcelona, Oikos - Tau, 1982. 365p.

LIMA, A.M.N. Estoque de carbono e frações da matéria orgânica do solo sob povoamento de eucalipto no Vale do Rio Doce - MG. Viçosa, MG, Universidade Federal de Viçosa, 2004. 109p. (Tese de Doutorado)

LU, X.Q.; HANNA, J.V. \& JOHNSON, W.D. Source indicators of humic substances: An elemental composition solid state ${ }^{13} \mathrm{C}$ CP/MAS NMR and Py-GC/MS study. Appl. Geochem, 15:1019-1023, 2000

MILORI, D.M.B.P.; MARTIN-NETO, L.; BAYER, C.; MIELNICZUK, J. \& BAGNATO, V.S. Humification degree of soil humic acids determined by fluorescence spectroscopy. Soil Sci., 167:739-749, 2002.

PÉREZ, M.G.; MARTÍN-NETO, L.; SAAB, S.C.; NOVOTNY, E.H.; MILORI, D.M.B.P.; BAGNATO, V.S.; COLNAGO, L.A.; MELO, W.J. \& KNICKER, H. Characterization of humic acids from a Brasilian Oxisol under different tillage by EPR, ${ }^{13} \mathrm{C}$ NMR, FTIR and fluorescence spectroscopy. Geoderma, 118:181-190, 2004
RICE, J.A. Humin. Soil Sci., 166:848-857, 2001.

RICE, J.A. \& MACCARTHY, P. Statistical evaluation of the elemental composition of humic substances. Organic Geochem., 17:635-648, 1991.

ROSSEL, R.A.; ANDRIULO, A.E.; SCHNITZER, M.; CRESPO, M.B. \& MIGLIERINA, A.M. Humic acids proprieties of an argiudoll soil under two tillage systms. Sci. Total Environ., 81/82:391-400, 1989.

SCHNITZER, M. \& GUPTA U.C. Determination of acidity in soil organic matter. Soil Sci. Soc. Proc., 27:274-277, 1965.

SENESI, N.; D'ORAZIO, V. \& RICA, G. Humic acids in the first generation of Eurosoils. Geoderma, 116:325-344, 2003.

SIERRA, M.M.S. \& GIOVANELA, M. A utilização da espectroscopia de fluorescência no estudo da matéria orgânica dissolvida nas águas naturais: Evolução e perspectivas. Química Nova, 19:294-300, 1995.

STEVENSON, F.J. Humus chemistry: Genesis, composition, reactions. 2.ed. New York, Willey, 1994. 496p.

TOMÉ JR., J.B. Manual para interpretação de análise de solo. Guaíba, Agropecuária, 1997. 247p.

VILLELA, D.M.; NASCIMENTO, M.T.; REZENDE, C.E.; NASCIMENTO, A.C.P.; MAZUREC, P.A. \& TESCH, E. Concentração e estoque de nutrientes na serrapilheira e no estrato rasteiro sob plantações de eucalipto (Corymbia citriodora (Hook) L.A. Jonhoson \& K.D. Hill), na Reserva Biológica União, RJ, após 6 anos de abandono. In: CONGRESSO NACIONAL, 55; ENCONTRO REGIONAL DE BOTÂNICOS DE MG, BA E ES, 26.,Viçosa, 2004. Anais. Viçosa, MG, 2004. CD-ROM

ZECH, W.; SENESI, N.; GUGGENBERGER, G.; KAISER, K.; LEHMANN, J.; MIANO, T.M.; MILTNER, A. \& SCHROTH, G. Factors controlling humification and mineralization of soil organic matter in the tropics. Geoderma, 79:117-161, 1997. 